\title{
Analysis of Heat Losses of Absorber Tubes of Parabolic through Collector of Shiraz (Iran) Solar Power Plant
}

\author{
M. Yaghoubi, F. Ahmadi, and M. Bandehee
}

\begin{abstract}
In this article heat losses of absorber tubes of parabolic trough collectors for the collector field of $250 \mathrm{~kW}$ Shiraz (Iran) solar thermal power plant is evaluated for various conditions. For analysis, both experimental measurements and numerical modeling are made to find the impact of failure of heat collecting tubes. The amount of heat losses are compared numerically for 3 different types of tubes; vacuum, lost vacuum (air) and broken glass (bare) tube. The experimental measured data are used to validate the numerical simulation. For temperature measurements around the glass tube and absorber tube an infrared thermograph (IR) camera is used. Thermal images are calibrated with measuring some local temperatures. For theoretical simulation a commercial code for thermal analysis of parabolic collectors are used. An absorber tube with vacuum reduces significantly the heat losses in comparison with broken tube or tube without vacuum. During power plant operation poor isolation or any glass tube failure should be avoided for any solar thermal power plants.
\end{abstract}

Index Terms-Heat loss, Parabolic trough collector, Thermal efficiency, Infrared (IR) camera.

\section{INTRODUCTION}

The current industrial growth and environmental impacts show that solar energy for solar thermal power plants is the most promising of the unconventional energy sources. The most common commercially available solar power plants use parabolic trough concentrators.

A parabolic collector includes the receiver tube, the concentrator, power transmition, collector structure. The receiver is the element of the system where solar radiation is absorbed and converted to thermal energy. It includes an absorber tube, its associated glass cover, and insulations at its end.

For the first $250 \mathrm{~kW}$ pilot solar thermal power plant in Shiraz, Iran, the collector circuit consists a field of 48 solar parabolic trough collectors such as shown in Fig. 1, arranged in modules operating in tracking mode and containing oil as their working fluid [1]. The working fluid in the receiver tube absorbs solar energy and transfers it to water in heat exchangers to produce hot water or steam. The receiver is covered by a glass tube to reduce thermal radiation as well as convection heat loss to the free air which moves around the receiver. To reduce further the heat losses from the absorber, air is evacuated from the space between absorber and glass cover [2]. Several researches have been performed to study different absorber tubes performance, such as porous finned absorber tubes [3]

Manuscript received October 9, 2012; revised December 24, 2012

M. Yaghoubi, F. Ahmadi, and M. Bandehee are with School of mechanical engineering, Shiraz, Iran (email: yaghoubi@shirazu.ac.ir, f_ahmadi@shirazu.ac.ir). and tubes with inserted twisted tapes[4]. The absorber tube of the present collector has $7 \mathrm{~cm}$ outer diameter and glass cover has $12 \mathrm{~cm}$ outer diameter. For the design condition described in Ref.[2], the working fluid approaches to $265^{\circ} \mathrm{C}$. Heat loss from glass cover to ambient air is by thermal radiation and mostly by convection. The surrounding air is usually turbulent and crosses the glass tube and exchange heat between glass outer surface and ambient air. Convection heat loss from the glass cover depends on the ambient wind flow, air temperature and glass cover temperature. The air may have low speed and hence free convection is dominant or it may have some momentum, in which case combined free and forced convection occurs. If the wind blows with some speed forced convection takes place. For most cases, such as the region of $250 \mathrm{~kW}$ Shiraz power plant the wind blows most of the time througho ut the year[1]. During the lifetime of a parabolic trough collectors power plant, some absorber segments lose vacuum and there after suffer from significant convective heat loss. In this study an IRThermography method is used to evaluate the heat loss of parabolic trough collectors tube by measuring the glass surface temperature of tubes. The results are compared with a numerical 3D model of a $4 \mathrm{~m}$ parabolic trough collectors for 3 different types of tube: 1-vaccum jacket tube, 2-lost vacuum tube, 3 - broken glass tube. This paper describes a combined conduction, convection, and radiation heat transfer model for the receiver tube. it includes the effects of nonuniform solar flux on the absorber tube, surface temperature of absorber tubes for 3 different types of tube which is mentioned earlier. For such positions which are not possible to measure experimentally with a thermograph camera, numerical simulation is used to find temperature field of the absorber surface. Different components of an absorber tube are illustrated in Fig. 2.

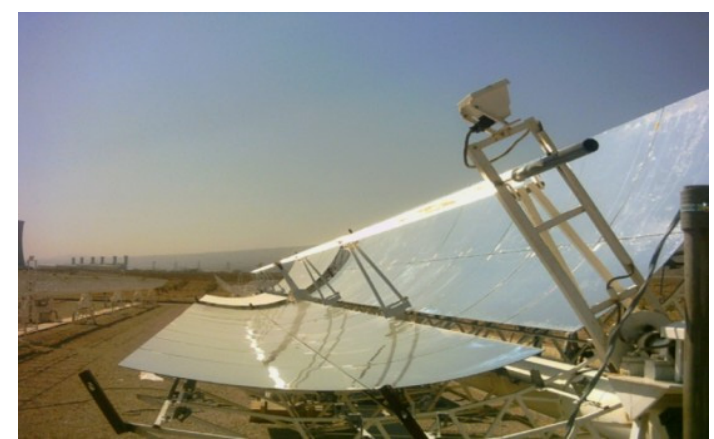

Fig. 1. Parabolic collector with absorber tube of Shiraz solar power plant [1]

\section{GOVERNING EQUATIONS}

Heat transfer from the absorber tubes include, 
qconv_g_sky and qrad_g_sky, the convective and radiative heat transfer loss from the outer surface of glass tube to the environment [6].

$$
\begin{gathered}
q_{\text {thermalloss }}=q_{\text {conv-g-sky }}+q_{\text {rad-g-sky }} \\
q_{\text {conv-g-a }}=h_{c}\left(T_{g}-T_{a}\right) \cdot A_{\text {glass }}
\end{gathered}
$$

where $T_{g}$ and $T_{a}$ are glass temperature and ambient temperature, $A_{\text {glass }}$ is glass envelope area and hc is the convective heat transfer coefficient of air,which is calculated from Mullick \& Nanda correlation[7]:

$$
h c=4 d^{-0.42} v^{0.5}
$$

where $V_{w}$ is the wind velocity in $\mathrm{m} / \mathrm{s}$ and $D$ is the outer diameter of glass cover in $\mathrm{m}$.

$$
q_{\text {rad_g_a }}=\sigma \cdot \varepsilon_{g} \cdot\left(T_{g}^{4}-T_{\text {sky }}^{4}\right) \cdot A_{\text {glass }}
$$

where $\sigma$ is Stephan Boltzman coefficient, $\varepsilon_{g}$ is glass envelope emissivity and $T_{s k y}$ is sky temperature. For turbulent oil flow inside the absorber, governing equations are continuity, momentum, Energy, RTE equations and $k-\varepsilon$ for turbulent modeling [6].

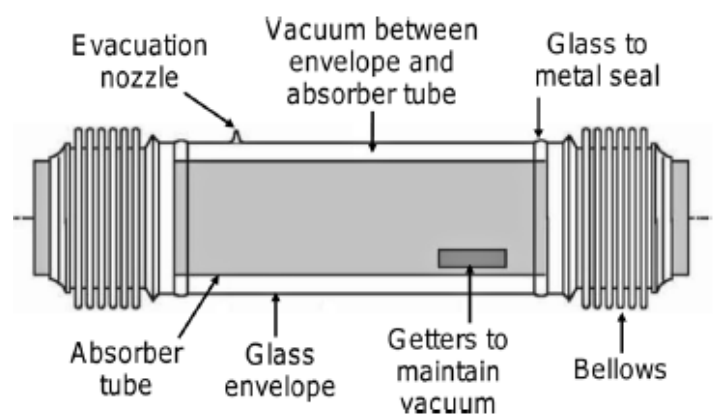

Fig. 2. Components of an absorber tube of parabolic trough colectors [5]

\section{HEAT LOSSES}

Experimental (Thermography) and numerical method are used to calculate heat loss for 3 different types of tube which are shown in Fig. 3- Fig. 5;

1) vacuum jacket tube

2) lost vacuum tube

3) broken glass tube

Shiraz parabolic trough collectors specification are tabulated in Table I.

TABLE I: COLLECTORS SPECIFICATIONS [8]

\begin{tabular}{|c|c|c|c|}
\hline Absorber tube length & $4.06 \mathrm{~m}$ & Absorptivity of absorber tube & 0.94 \\
\hline Outer diameter of absorber tube & $7 \mathrm{~cm}$ & Geometric concentration ratio $\left(\mathrm{G}_{\mathrm{c}}\right)$ & 14 \\
\hline Inner diameter of absorber tube & $6.56 \mathrm{~cm}$ & Aperture of collector & $3.1 \mathrm{~m}$ \\
\hline Outer diameter of glass tube & $12.5 \mathrm{~cm}$ & Width & $3.4 \mathrm{~m}$ \\
\hline Inner diameter of glass tube & $11 \mathrm{~cm}$ & Focal length & $88 \mathrm{~cm}$ \\
\hline Emissivity of absorber tube & 0.15 & & \\
\hline
\end{tabular}

The absorber is made by SCHOTT Factory in Germany. The absorber tube is made by AISI 316L [8]. The working fluid used in the absorber tube is Behran-oil with properties mentioned in Ref.[8].

\section{A. IR-Thermography Method (Experimental)}

A Testo 881 IR-Thermograph camera is used for glass envelope surface temperature measurements. Because the receiver glass envelope is essentially opaque to infrared (IR) radiation, all the thermal losses from the receiver must pass, via conduction, through the glass envelope. As a result, the radiant and convective thermal losses from the receiver are directly related to the glass envelope temperature and it does not matter what is happening inside the glass tube(for example, the type and quality of the selective coating, whether the vacuum is good or bad, or the HTF fluid temperature). The thermal losses can be correlated directly with the glass envelope temperature for known air temperature and wind speed. The procedure required collectors to be defocused while measurements were taken on each receiver with a hand-held IR temperature measurement gun. The collector had to be defocused so that the crews were able to get close enough to take the measurements. The IR gun reads the temperature of a relatively small spot. Several readings were taken on each receiver to obtain a more representative average glass temperature. The IR camera measures the emitted IR radiation from an object. Because the emitted radiation is a function of the surface temperature of the object, the temperature of the surface can be determined if the emittance of the surface is known, for this many cross sections has been selected on each receivers. For each cross-section, the average temperature is determined. This temperature is assumed to be the glass temperature of the receiver at this cross section. The average value for each of the cross- sections is used to calculate average glass temperatures for each receiver.

Fig. 3-5 shows IR images taken of 3 different types of parabolic trough receiver. From the images, the receiver, receiver supports, mirrors, and sky are clearly identifiable. The color of the image represents the intensity of the IR signal and temperature. The results of thermography method are tabulated in Table II.

\section{B. Numerical Method}

In this study, by using common CFD software, the three mentioned absorber tubes are modeled for linear collectors of Shiraz solar power plant condition. Navier Stokes and energy equations are solved to analyze the fluid inside the tubes. Discrete ordinate model is used for analyzing radiation in the vacuum space between the absorber tube and the transparent glass tube and ultimately the $\mathrm{k}-\varepsilon$ model is considered for turbulence modeling. The model is validated, based on published reports of experimental data [9].

\section{1) Boundary Condition}

In our solution, a $4 \mathrm{~m}$ absorber tube is considered. Boundary condition is clarified in Fig. 6. It must be mentioned that the non-uniform distribution of radiation heat flux (Fig. 6), is considered, around the absorber tube which is a function of local concentration ratio (Fig. 7) and the rim angle of PTC's. The wind velocity is considered 1.5 $\mathrm{m} / \mathrm{s}$ and the inlet temperature of oil is assumed $200{ }^{\circ} \mathrm{C}$. 


\section{2) Grid Study}

Different type of models and number of grids, were studied. Finally in a grid with dimensions $(400 \times 3148)$ of the type $\mathrm{H}-\mathrm{O}$, the independency of the grid, is approved as shown in Fig. 6.

It is worth to say that the equations of momentum and energy are discretized in-second order upwind method and also SIMPLE algorithm is used to solve velocity and pressure simultaneously. Accuracy of results are obtained for the momentum and energy and radiation in the orders $6 \mathrm{E}-10$ and $8 \mathrm{E}-10$ and $8 \mathrm{E}-10$ respectively [10].

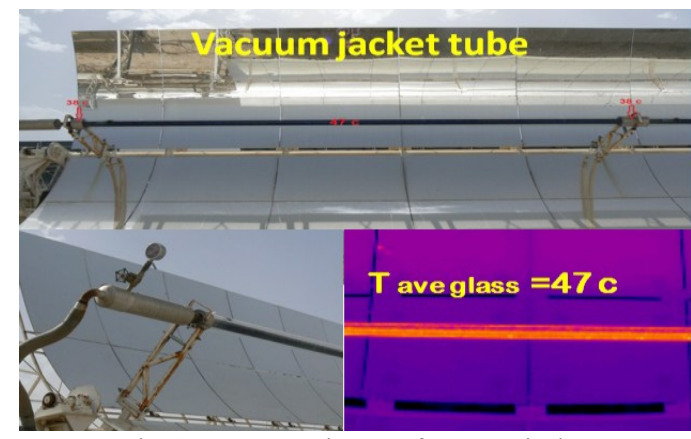

Fig. 3. IR-camera image of vacuum jacket

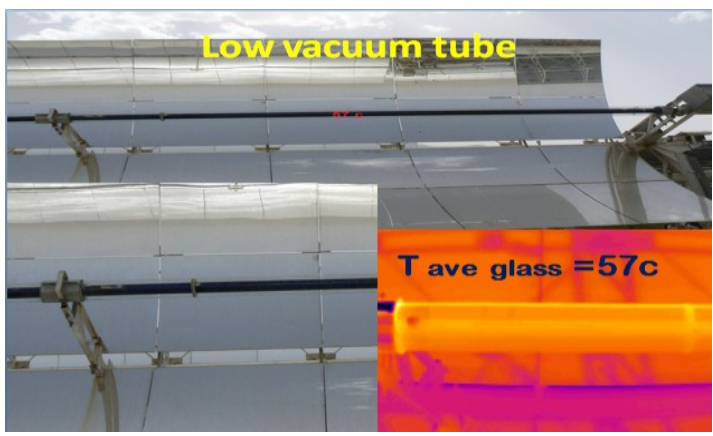

Fig. 4. IR-camera image of lost vacuum tube

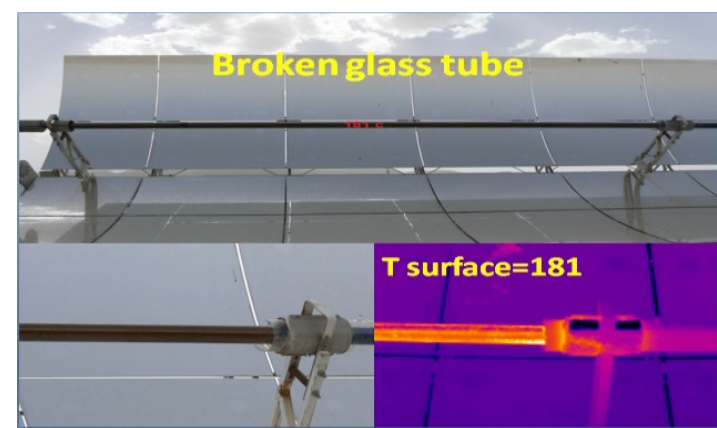

Fig. 5. IR-camera image of broken glass tube

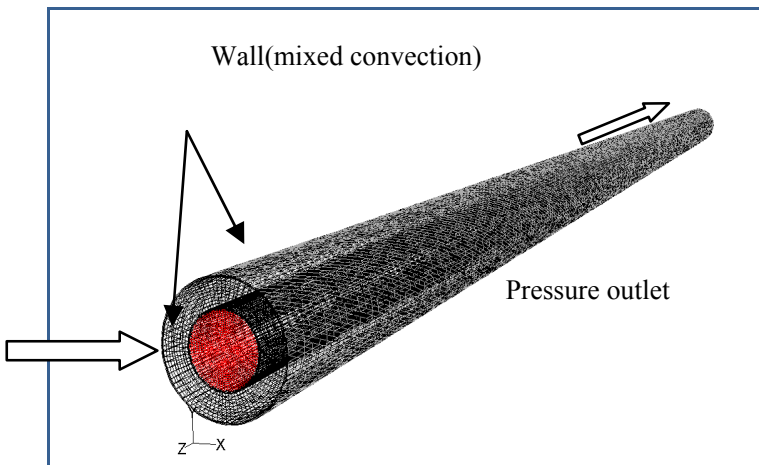

Fig. 6. The grid and boundary conditions, used in numerical solution

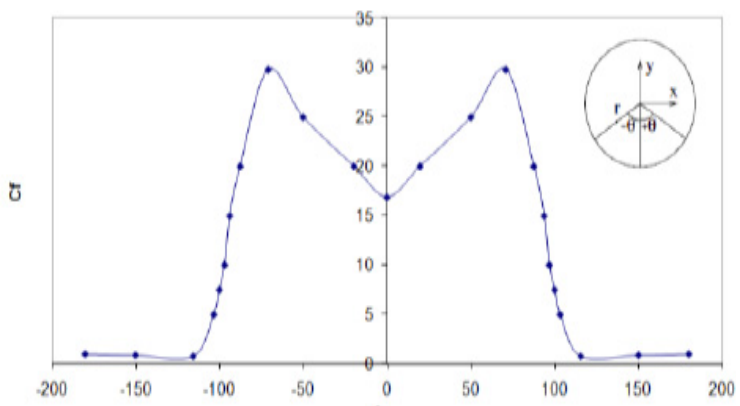

Fig. 7. Local concentration ratio of shiraz parabolic trough collectors[8]

TABLE II: EXPERIMENTAL RESULTS FROM IR-THERMOGRAPHY METHOD FOR HEAT LOSS CALCULATION

\begin{tabular}{|c|c|c|c|}
\hline & Vacuum jacket tube & Lost vacuum tube & Broken glass tube \\
\hline date & $2012 / 05 / 26$ & $2012 / 05 / 26$ & $2012 / 05 / 26$ \\
\hline time & $15: 03$ & $15: 37$ & $20: 49$ \\
\hline Inlet oil temperature $\left({ }^{\circ} \mathrm{C}\right)$ & 206 & 204 & 200 \\
\hline Outlet oil temperature $\left({ }^{\circ} \mathrm{C}\right)$ & 198 & 6.56 & 201 \\
\hline humidity & 8.44 & 36.82 & 7.44 \\
\hline Sun angle & 28.92 & 800 & 39.36 \\
\hline Direct intensity $\left(\mathrm{W} / \mathrm{m}^{2}\right)$ & 836 & 33 & 37 \\
\hline Ambient temperature $\left({ }^{\circ} \mathrm{C}\right)$ & 33 & 1.5 & \\
\hline Wind velocity $(\mathrm{m} / \mathrm{s})$ & 1.5 & 233.64 & \\
\hline Heat loss $(\mathrm{W} / \mathrm{m})$ & 153.11 & & \\
\end{tabular}

TABLE III: RESULTS OF NUMERICAL SOLUTION

\begin{tabular}{|c|c|c|c|c|c|c|c|c|c|}
\hline & Broken glass tube & 483.5 & 303 & 626.23 & 15.78 & 1.5 & 11.73 & - & - \\
\hline & Collector number & $\begin{array}{c}\mathrm{T}_{\text {surf(ave) }} \\
(\mathrm{K})\end{array}$ & $\begin{array}{l}\mathrm{T}_{\mathrm{amb}} \\
(\mathrm{K})\end{array}$ & $\begin{array}{c}\mathrm{Q}_{\text {loss }} \\
(\mathrm{W} / \mathrm{m})\end{array}$ & $\begin{array}{c}\mathrm{U}_{\mathrm{L}(\text { overall })} \\
\left(\mathrm{W} / \mathrm{m}^{2} \cdot \mathrm{k}\right)\end{array}$ & $\begin{array}{l}\text { Wind velocity } \\
(\mathrm{m} / \mathrm{s})\end{array}$ & Outside heat transfer coefficent & $\begin{array}{c}\mathrm{T}_{\min } \text { glass } \\
(\mathrm{K})\end{array}$ & $\begin{array}{c}\mathrm{T}_{\max } \text { glass } \\
(\mathrm{K})\end{array}$ \\
\hline \multirow{2}{*}{ numerical } & Vaccume tube & 489.1 & 303 & 219.36 & 5.36 & 1.5 & 11.73 & 326 & 342 \\
\hline & Lost vaccume tube & 487 & 303 & 288.86 & 7.15 & 1.5 & 11.73 & 332 & 347 \\
\hline
\end{tabular}

TABLE IV: COMPARISON OF NUMERICAL AND EXPERIMENTAL RESULTS

\begin{tabular}{|c|c|c|c|}
\hline & Vacuum tube $(w / m)$ & Lost vacuum tube(W/m) & Broken glass tube( W/m) \\
\hline Loss(experimental) & 153.11 & 223.64 & 522.17 \\
\hline Loss(numerical) & 219.36 & 288.86 & 626.23 \\
\hline Reflected energy into absorer tube & 2842 & 2720 & 2675 \\
\hline Loss percentage (experimental) & 5.3 & 8.2 & 19.5 \\
\hline Loss percentage (numerical) & 7.7 & $58.5 \%$ & 23.4 \\
\hline Collectors performance(numerical) & $61 \%$ & $46 \%$ & \\
\hline
\end{tabular}




\section{RESULTS}

Results of numerical solution are presented in Table III. Overall heat transfer coefficient is calculated from equation(5) [11]:

$$
U_{L}\left(w / m^{2}-k\right)=\frac{Q_{\text {loss }}}{A_{\text {abs }}\left(T_{\text {abs }}-T_{\text {amb }}\right)}
$$

where $Q$ loss is the amount of heat loss, Aabs is absorber area and Tabs , Tamb are absorber outer surface temperature and ambient temperature. Figs. 8-9 present the cross sectional temperature contours in middle of the vacuum jacket tube and the lost vacuum jacket tube.

As illustrated in Fig. 10 glass envelope temperature for the lost vacuum tube is much higher than for vacuum jacket tube which results in higher heat dissipation rate.

Calculations from experimental measurments and the numerical solution are compared in Table IV.

Table IV shows that the amount of heat loss for numerical solution is higher than experimental measured data. The main reason which must be taken in to account is, defocusing collectors during experimental measurements which lead to lower glass envelope surface temperature in comparison with a tracking collector. Glass surface temperature calculated by the numerical solution is about 5 8 degree centigrade higher than experimental measured values. Collectors performance reduced considerably when the glass cover was removed or broken.

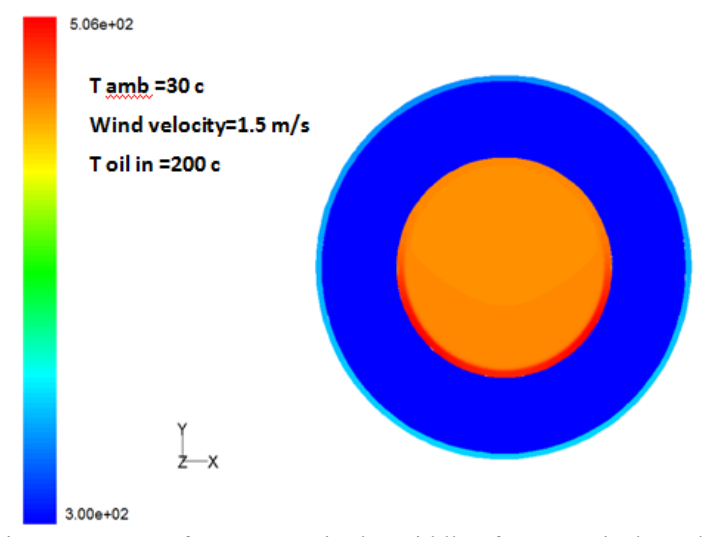

Fig. 8. Contour of temprature in the middle of vacuum jacket tube

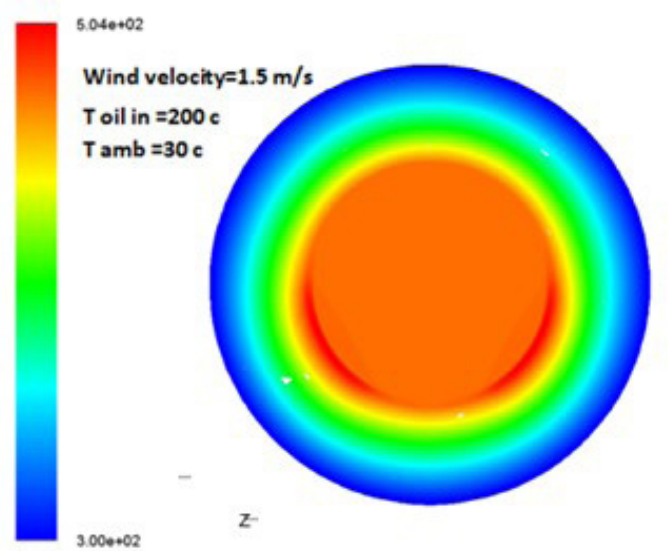

Fig. 9. Contour of temprature in the middle of lost vacuum tube

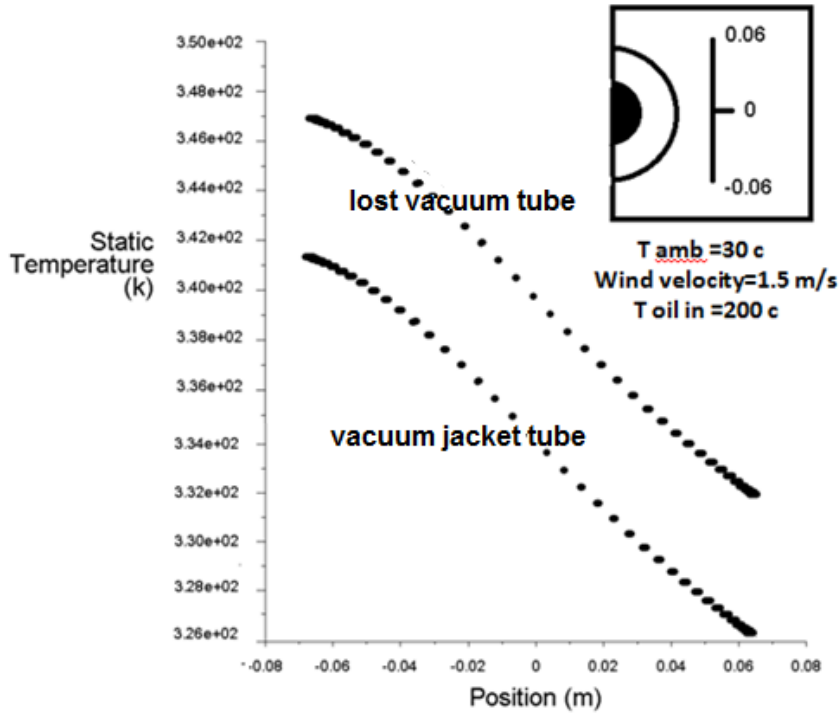

Fig. 10. Comparison of vacuum jacket tube and lost vacuum tube glass envelope surface temperature

\section{CONCLUSION}

It is observed that from numerical and experimental analysis of heat loss of absorber tubes of Shiraz parabolic trough collectors:

1) The heat loss of lost vacuum tube is $40 \%$ higher than vacuum jacket tube, which leads to $3-5 \%$ reduction in the collector thermal performance.

2) The amount of heat losses for broken glass tube has a considerable increment. Numerical calculations show 12$16 \%$ reduction in thermal performance for broken glass tube.

\section{REFERENCES}

[1] N. Naeeni and M. Yaghoubi, "Analysis of wind flow around a parabolic collector (2) Fluid flow," Renewable Energy, vol. 32, pp. 1259-1272, 2007.

[2] M. Roesle, "Numerical analysis of heat loss from a parabolic trough absorber tube with active vacuum system," J. Sol. Energy Eng., vol. 133, August 2011.

[3] K. S. Reddy and G. V. Satyanarayana, "Numerical study of porous finned receivers for parabolic trough collectors," Engineering Application of Computational Fluid Mechanic, vol.2, 2008.

[4] Y. W. Chiu and J. Y. Jang, "3D numerical and experimental analysis for thermal-hydraulic characteristics of flow inside a circular tube with different tune insets," Applied Thermal Engineering, vol. 29, pp. 250-258, 2009.

[5] S. A. Kalogirou, "Solar thermal collectors and applications, Prog," Energy Combust.Sci., vol. 30, pp. 231-295, 2004.

[6] S. D. Odeh, G. L. Morrison, and M. Behnia, "Modelling of parabolic trough direct steam generation solar collectors," Sol. Energy, vol. 62, no. 6, pp. 395-406, 1998.

[7] S. C. Mullick and S. K. Nanda, "An improved technique computing the heat loss factor of a tubular absorber," J Solar Energy, vol. 42, pp. 1-7, 1989.

[8] M. Yaghoubi and M. Akbari, "Three dimensional thermal expansion analysis of an absorber tube in a parabolic trough collector," SoLAR PACE, Spain, 2011.

[9] V. Dudley, G. Kolb, M. Sloan, and D. Kearney, "SEGS LS2 solar collector - test results,Report of Sandia National Laboratories," SANDIA94-1884, USA, 1994.

[10] A. A. Golneshan, M. Bandehee, "The numerical analysis of adding c- shape plates inside the linear parabolic trough collectors absorber tube(1)," Heat and mass transfer conference, Zahedan, Iran, 2012.

[11] F. P. Incorpera and D. P. Dewitt, "Introduction to heat transfer," John Wiley \& Sons, 1985. 


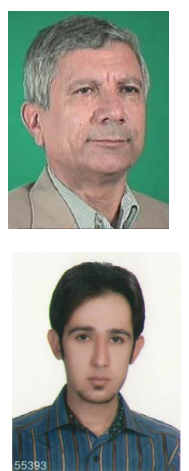

Prof. Mahmood Yaghoubi was born on October 17 1945 in Iran. He got his PHD in Purdue University, USA, 1987. His Research areas are energy, exergy analysis, computational heat transfer and solar energy.

Fariborz Ahmadi was born on July, 01, 1987 in Iran $\mathrm{He}$ is the MSc. of Mechanical Engineering of Shiraz University His field of research includes experimental solar energy and heat transfer, experimental fluid dynamic, computational fluid dynamid, computational heat transfer, exergy analysis.

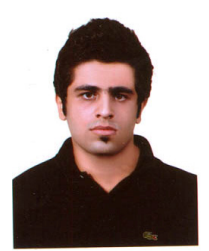

Mohammad Bandehee was born on November, 20, 1985 in Iran. He is the MSc. of Mechanical Engineering of Shiraz University. His Field of research includes solar energy, exegy analysis, computational fluid dynamic and computational heat transfer. 